\title{
O puro sujeito do conhecer e a arte*
}

\section{The pure subject of knowledge and the art}

\author{
Matthias Koßler
}

Professor da Johannes Gutenberg-Universität Mainz e

Presidente da Schopenhauer-Gesellschaft (Alemanha)

Tradução de

Jair Barboza

Professor da Universidade Federal de Santa Catarina (UFSC)

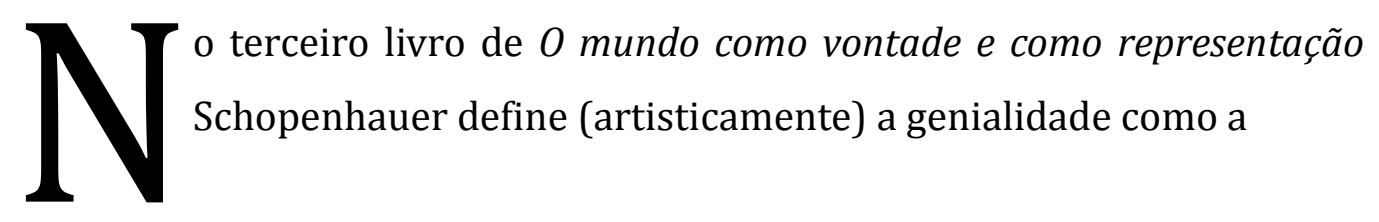

capacidade de proceder de maneira puramente intuitiva, de perder-se na intuição e de afastar por inteiro dos olhos o conhecimento que existe originariamente apenas para o serviço da vontade, isto é, deixar inteiramente de lado o próprio interesse, o próprio querer e os seus fins, com o que a personalidade se ausenta completamente por um tempo, restando apenas o puro sujeito que conhece, claro olho cósmico ${ }^{1}$.

Essa concepção, atacada por Nietzsche como hipócrita [heuchlerisch], de um „conhecimento imaculado“2, tem o seu fundamento no transcendentalismo de Schopenhauer, segundo o qual "o sujeito que conhece de modo estrito"3 é o "sustentáculo do mundo"; ora, visto que o sujeito do conhecimento nessa acepção é a condição de espaço, tempo, pluralidade e individualidade, a ele mesmo não cabem tais propriedades ${ }^{4}$ Eu gostaria de percorrer em minha conferência o caminho que vai desde o "sujeito que conhece em sentido estrito", com o qual Schopenhauer pretende vincular-se a Kant, até o "puro sujeito que conhece destituído de vontade“, por Nietzsche criticado.

\footnotetext{
* Conferência de abertura do VII Colóquio Internacional Schopenhauer, ocorrido na Universidade Federal da Bahia (UFBA), em Salvador, de 26 a 30 de outubro de 2015.

${ }^{1}$ SCHOPENHAUER, A. WWV I, 219.

2 NIETZSCHE, F. Also sprach Zarathustra, KSA 4, 156 ff.

${ }^{3}$ SCHOPENHAUER, A. WWV II, 18.

${ }^{4} \mathrm{Cf}$. SCHOPENHAUER, A. WWV I, $5 \mathrm{f}$.
} 


\section{a. Transcendentalismo}

"Puro" sujeito do conhecimento não significa um sujeito sem objeto. Para Schopenhauer, o idealismo transcendental repousa em que sujeito e objeto são correlatos, portanto, que „ser-sujeito significa a mesma coisa que ter um objeto, e ser-objeto significa a mesma coisa que ser conhecido por um sujeito“. Mas, enquanto conhecemos objetos, o sujeito do conhecer, que somos nós mesmos, permanece incognoscível. Como correlato das quatro diferentes classes de objeto da Dissertação, o sujeito que conhece pode ser designado como entendimento, sensibilidade, razão e consciência de si; porém, tais termos nada dizem sobre um conhecimento do sujeito, mas são apenas expressões para diversos tipos de representação que reúnem determinados objetos e o seu respectivo sujeito correlato. É impossível conhecer o sujeito do conhecimento, porque ele, como o correlato necessário do objeto, jamais pode tornar-se objeto. Excetuando-se as descrições que mostram as diversas classes de objeto, só podemos fazer enunciados negativos sobre o sujeito do conhecer. Na medida em que todas as formas do princípio de razão, e com isso todas as determinações formais de um objeto, dependem do sujeito que conhece, tais formas não lhe cabem: o sujeito do conhecer não está no espaço nem no tempo, não está submetido à causalidade, não possui matéria alguma nem individualidade alguma, já que espaço e tempo constituem o principium individuationis. O conceito de sujeito do conhecer corresponde ao sujeito transcendental de Kant, e suas determinações negativas são expressões de que o sujeito do conhecer, como condição de possibilidade dos objetos dados da experiência, sobrepõe-se à experiência.

Em oposição a Kant, entretanto, Schopenhauer não limita a experiência a objetos dados no sentido externo. Apesar de não termos conhecimento algum sobre o sujeito do conhecer, podemos no entanto conhecer a nós mesmos, através da experiência interna, como sujeito do querer. Dessa maneira, o sujeito do querer é objeto do sujeito do conhecer e estamos ao mesmo tempo imediatamente conscientes da identidade entre os dois. Explicitar a identidade, que na Dissertação 


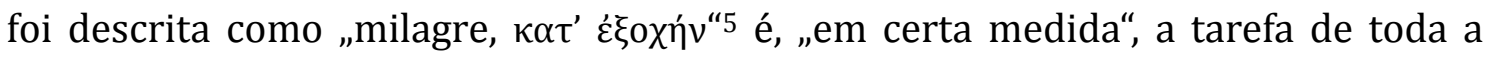
obra principal de Schopenhauer.

Decisivo para a explicitação da identidade entre sujeito do querer e sujeito do conhecer é a consciência do próprio corpo, que conduz a um conhecimento „de ordem inteiramente outra“; cuja verdade específica é descrita por Schopenhauer como verdade filosófica, $\kappa \alpha \tau^{\prime} \varepsilon \dot{\xi} \xi \chi \eta \eta^{\prime}$, que, por assim dizer, substitui o anterior discurso do, por assim dizer, um „milagre“. Esse conhecimento não pode ser classificado em nenhuma das formas do princípio de razão suficiente, todavia pode ser retrosseguido ao conhecimento do sujeito do querer. Já na Dissertação o conhecimento do sujeito que quer foi descrito como uma modalidade bem específica de conhecimento. De um lado, naturalmente, porque, com a identidade entre sujeito e objeto, o objeto - como Schopenhauer formula mais tarde - „cessa justamente de ser objeto“6. De outro lado porque, já então, o sujeito do querer só foi denominado objeto „com uma significativa limitação“, pois não é o sujeito do querer como tal que é objeto do sentido interno, mas apenas os atos isolados da vontade, aos quais aplica-se primeiramente um sujeito unitário desses atos. 0 sujeito do querer, como dessa forma é inferido a partir dos seus atos como seu fundamento, é o caráter do indivíduo.

$\mathrm{Na}$ sua obra principal, Schopenhauer procura resolver esse problema na medida em que introduz uma nova relação entre vontade e ação, relação esta que substitui a relação causal do primeiro esboço. Essa relação é caracterizada como „reflexo“, „aparência“ ou „visibilidade“ e designada com o terminus technicus „objetivação“. O modelo é a relação entre o ato da vontade, percebido no sentido interno, e a ação do corpo que o acompanha, que é ao mesmo tempo é percebida pelo sentido externo; de modo que a ação corporal nada é senão a aparência exterior de um processo interiormente vivido. E assim como a ação isolada do corpo é a visibilidade (não a consequência) do ato isolado da vontade, assim também o corpo inteiro é a visibilidade ou objetivação da vontade como um todo. Dessa forma, sujeito da vontade e corpo são idênticos, são simplesmente o lado interior e exterior da mesma coisa. Que o objeto da consciência de si cesse de ser objeto é isto evitado pelo fato de o sujeito da vontade não ter mais de ser objeto do

${ }^{5}$ SCHOPENHAUER, A. Diss. $72 \mathrm{f}$.

${ }^{6}$ Ibidem. 
conhecer no sentido estrito e imediato do termo. 0 próprio corpo é objeto da consciência de si na medida em que está ligado pelo processo de objetivação ao sujeito do querer. Para ser mais preciso: não é o sujeito do querer, nem o corpo como este aparece no espaço e no tempo, que é o objeto propriamente dito da consciência de si, mas o processo mesmo de objetivação, e que constituti a identidade de ambos é que é o objeto da consciência de si (voltaremos a isso quando da explicitação da Ideia estética). A problemática unidade do sujeito que quer é assim assegurada pela unidade do corpo.

Não é aqui o lugar para tratar pormenorizadamente do conhecimento do corpo como fundação da metafísica da vontade. Vou me limitar aos aspectos que são de significação para o nosso tema. Nesse sentido é importante a circunstância de que o sujeito que quer e o sujeito que conhece, que coincidem, não devem ser separados do corpo. 0 ser humano não é uma "cabeça de anjo alada destituída de corpo" e "seu conhecimento, sustentáculo condicionante do mundo inteiro como representação, é no todo intermediado por um corpo..." Na medida em que o sujeito do conhecer liga-se ao corpo, isso afasta Schopenhauer da concepção kantiana de sujeito transcendental. Em Kant o sujeito transcendental nada é senão a unidade da apercepção, a condição lógica de qualquer síntese de representações. É rigorosamente diferente do „eu“ empírico e individual que é determinado através de suas ações, experiências e de sua aparência corporal. Schopenhauer, ao contrário, vincula o sujeito que conhece com o sujeito que quer e o corpo. Se a identidade do sujeito do querer com o corpo foi exposta, permanece no entanto ainda carente de esclarecimento a coincidência entre o sujeito que conhece e o sujeito que quer. No ensaio Sobre a vontade na natureza há duas expressões aparentemente contraditórias que complicam ainda mais a coisa. Em primeiro lugar, ele faz a afirmação de que devemos ver como „a verdade fundamental da minha doutrina"7 o fato de o conhecimento ${ }^{8}$ ser condicionado pela vontade; poucas páginas adiante, ao contrário, a completa separação da vontade do conhecimento é designada como o „traço fundamental da minha doutrina“ Antes de colocarmos a questão sobre o que significa „puro sujeito do conhecer“, na medida em que não pode ser o sujeito transcendental no sentido de Kant e Fichte, temos de lançar um

${ }^{7}$ Cf. SCHOPENHAUER, A. N, 3.

${ }^{8}$ Cf. Idem, 19. 
olhar para a metafísica da vontade.

\section{b. 0 intelecto a serviço da vontade}

A relação entre vontade e corpo é descrita por Schopenhauer, com conceitos kantianos, como a relação entre coisa em si e aparência. É de todos conhecido que Schopenhauer transmite, mediante analogia, a relação entre a vontade e o próprio corpo a todas as representações, de tal modo que „aquilo a denominarmos em nós vontade" é a coisa em si de todas as aparências ou a essência una do mundo ${ }^{9}$. À parte uma análise da complexa estrutura das assim chamada „conclusão analógica“, o seu resultado é a dependência, do mundo como representação, da vontade. 0 próprio corpo é parte do mundo e, na medida em que o conhecer está ligado ao corpo, o intelecto também encontra-se na dependência da vontade. „Pois o intelecto é tão transitório quanto o cérebro, do qual é produto ou antes ação. O cérebro no entanto é, como todo o organismo, produto ou aparência, numa palavra, coisa secundária à vontade, única que é imperecível“10. Esta citação é elucidativa do procedimento de Schopenhauer no segundo livro de $O$ mundo como vontade e como representação. Schopenhauer manuseia e transforma a relação entre essência e aparência num tipo de produção e, sobre essa base, erige ele sua doutrina central do primado da vontade sobre o intelecto. Essa doutrina é, ao mesmo tempo, metafisicamente fundada ali no fato de a objetivação da vontade como coisa em si aparecer na forma de uma evolução de gêneros e espécies que objetivam a vontade de um modo cada vez mais distinto até os animais e humanos dotados de entendimento. 0 intelecto é, com isso, um instrumento na luta pela sobrevivência, produzido pela vontade metafísica em vista de objetivar a si mesma numa diversidade de aparências. A vontade mostra-se nos indivíduos como Vontade de vida. [Por outro lado, Schopenhauer aduz uma profusão de observações psicológicas em vista de demonstrar o primado da vontade sobre o intelecto e retroceder esse primado ao seu fundamento metafísico. A consequência é que o intelecto, como um produto do cérebro, que por sua vez é, em certa medida, „produto“ da vontade, está ele intelecto inteiramente a serviço da vontade, na luta 
pela sobrevivência e para disponibilizar motivos e desejos à vontade.

A função serviçal do intelecto é realizada através do princípio de razão suficiente. Enquanto na sua Dissertação o princípio de razão foi tomado como forma originária da ciência, na filosofia madura ele é a expressão da Vontade de vida. Na medida em que institui diferentes formas de razão suficiente, o intelecto tem a possibilidade de relacionar todas as representações ao interesse da vontade individual; e, com a faculdade de razão, também podem ser representados à vontade motivos que são independentes da presença de objetos reais.

Já que a maneira como o entendimento e a razão são ativos depende da vontade, isso abre a possibilidade de um outro modo de conhecimento que não está submetido ao princípio de razão; com outras palavras: abre-se espaço para o pensamento de que o intelecto pode abandonar o serviço da vontade. Pois se a vontade como coisa em si é livre, porque não está submetida ao princípio de razão, então o modo de conhecimento que está a serviço da vontade não é um estado inexorável, mas está sob a potência do seu senhor. Naturalmente isso não deve ser entendido como se o indivíduo pudesse decidir se ele conhece ou não conforme o princípio de razão. A liberdade que subjaz a essa possibilidade é a liberdade da vontade como coisa em si, que vale como livre a partir do mesmo fundo pelo qual também tem de ser vista como não individual. 0 caminho que poderia conduzir a um modo de conhecimento independente da vontade não pode, portanto, ser procurado na decisão do indivíduo mas na sua capacidade em tornar-se consciente da própria independência da vontade e, em verdade, através do conhecimento mesmo. Pois esse aspecto do conhecimento de si parece já afastar-se do serviço da vontade.

A alternativa de um intelecto independente da vontade evita que a concepção de um sujeito transcendental se perca numa perspectiva naturalista, na medida em que relativiza o discurso de um conhecimento corporalmente vinculado. No enunciado de que o intelecto é „produzido“ pelo organismo, que por sua vez é „produto“ da vontade, exprime-se um modo de pensamento que ele mesmo é conforme o princípio de razão. 0 processo de objetivação da vontade é assim pensado causalmente. Todavia, o resultado das ponderações da Dissertação foi o de que não pode haver tipo algum de causalidade entre a vontade como coisa em si e a aparência. 0 modo e a maneira como, no segundo livro de $O$ mundo como 
vontade e como representação, é pensada a relação entre vontade e aparência, deve, por conseguinte, ser vista como inadequada. Neste ponto surge a questão sobre se há indícios para um outro modo de consideração que não está submetido ao princípio de razão e que estaria na condição de apreender mais adequadamente a objetivação da vontade. Schopenhauer diz que um tal tipo de conhecimento é para ser encontrado na contemplação estética e na arte.

Dessa forma, a apreensão do mundo como representação como até agora foi exposta, no sentido do princípio de razão, deve ser complementada através da segunda consideração do mundo como representação: „A representação independente do princípio de razão: a Ideia platônica: o objeto da arte." E, visto que individualidade, serviço da vontade e relação causal pertencem ao domínio determinado pelo princípio de razão, emerge uma significação de „puro conhecimento" que até então não fora objeto de investigação: com a interrupção do serviço que o intelecto faz para a vontade, suspende-se a relação do conhecimento com a vontade individual e o que permanece é o puro conhecer em si mesmo. Apenas o puro conhecer neste sentido é que pode apreender tanto a vontade como um todo e o mundo como um todo quanto a relação entre os dois; já o intelecto a serviço da vontade limita-se a conhecer o que o ser humano quer aqui e agora jamais o que o ser humano quer em geral - e, com isso, correspondentemente, o intelecto apreende apenas representações particulares. „Porém, o único autoconhecimento da vontade no todo é a representação no todo, o inteiro mundo intuitivo. Este é a objetidade, a manifestação, o espelho da vontade"11. [Tais palavras, com as quais Schopenhauer transita pelo terceiro livro de $O$ mundo como vontade e como representação, dedica à estética, comprovam com plena distinção que o real autoconhecimento é primariamente alcançado através da contemplação estética. Puro conhecer, exclusiva e em si mesmo como conhecer, retrocede ao conceito aristotélico de theoria, que após si traçou uma longa tradição de pensamento especulativo na Idade Média. Nietzsche critica, no capítulo Do conhecimento imaculado de Assim falou Zaratustra, a ressuscitação desse puro conhecimento na estética de Schopenhauer como ilusão. Para poder situar Schopenhauer no âmbito do tratamento dessa questão deve-se perguntar o que é o

11 SCHOPENHAUER, A. WWV I, 196. 
sujeito nesse sentido do puro conhecer.

\section{c. 0 puro sujeito do conhecer livre de vontade}

Em princípio, Schopenhauer não explica como ocorre a mudança do conhecimento submetido ao princípio de razão para o conhecimento livre de vontade. Parece também não poder ser de outro modo, pois, se ocorrem explicações segundo o princípio de razão, estas que não podem ultrapassar o domínio de sua validade. Por isso o conhecimento livre de vontade é considerado como uma exceção, dito de modo mais vigoroso: como „anomalia“ [Abnormität] ${ }^{12}$. A mudança de um modo de conhecimento para um outro no qual o conhecimento „se liberta do serviço da vontade“, dá-se de maneira imediata, „ocorre subitamente“ e „de um só golpe“13. Apenas as consequências da mudança podem ser analisadas e ligadas com as condições da perspectiva de um conhecimento que é apenas a determinação negativa do conhecimento livre de vontade. Este conhecimento livre de vontade implica a ausência de espaço, tempo e causalidade, de individualidade e de relação com a vontade.

A contemplação estética, para Schopenhauer, preenche, como contrapartida do conhecimento comum, tais condições; ele chega a essa convicção através de uma análise do fenômeno. Na consideração estética de um objeto empírico não nos interessa se o objeto nos propicia vantagem ou desvantagem. Não estamos interessados na sua existência mas o que nos absorve é exclusivamente a sua consideração. E, já que os nossos interesses, as nossas aversões e os nossos temores constituem nossa individualidade, que por sua vez espelha-se no nosso corpo, sentimos na visão do belo como se nossa individualidade se perdesse por instantes na contemplação. A contemplação estética não pode ser deliberadamente produzida; como metaforicamente escreve Schopenhauer: „Diante de um quadro, cada um tem de postar-se como se fora diante de um príncipe, aguardando se este falará, e o que, para ele; e, como diante dele, também não lhe dirigir a palavra: pois senão ouviria apenas a si mesmo"14. Por fim, consideramos o objeto empírico não como uma aparência isolada, mas como representante de todas as aparências

${ }^{12}$ Cf. SCHOPENHAUER, A. WWV II, 431.

${ }^{13}$ SCHOPENHAUER, A. WWV I, 209, 211.

${ }^{14}$ SCHOPENHAUER, WWV II, 463. 
singulares de uma espécie, que Schopenhauer denomina „Ideia platônica“.

Para Schopenhauer o fenômeno da contemplação estética comprova pois a realidade do conhecimento livre de vontade. Na medida em que Schopenhauer interpreta esse fato diante do pano de fundo das ponderações estabelecidas no limite da doutrina do conhecimento até então desenvolvida, situa ele o puro sujeito do conhecimento, e a Ideia como seu objeto, na estética. Ambos, assim como a sua referência recíproca, repousam fora do espaço e do tempo e, com isso, fora da individualidade e da causalidade. Em vez de uma determinação da relação entre sujeito e objeto, como referência do motivo à vontade individual, Schopenhauer emprega metaforicamente a expressão „espelhar“ que também já fora usada para caracterizar a relação não-causal entre vontade como coisa em si e aparência. A contemplação estética implica que a pessoa ,...permanece apenas como puro sujeito, como claro espelho do objeto; então é como se apenas o objeto ali existisse, sem alguém que o percebesse, e não se pode mais separar quem intui da intuição, pois ambos se tornaram uma coisa só, na medida em que toda a consciência é integralmente preenchida e tomada por uma única imagem intuitiva ${ }^{15}$. 0 espelho não é aqui para ser tomado como objeto de vidro e metal ou como espelho d'água, que possuem diversas características, dentre elas também a de poderem espelhar; mas o espelho é aqui considerado apenas sob a determinação de ser algo em que se mostram todas as coisas como elas são. Nesse sentido o sujeito nada é senão a visibilidade ou o médium do objeto.

Na medida em que Schopenhauer interpreta dessa maneira a contemplação estética, vincula ele a correlação de sujeito e objeto, como esta correlação funda o transcendentalismo, com a objetivação da vontade como espelhamento e com a identidade entre sujeito e objeto na consciência de si. A contemplação estética, como antes citado é, com isso, o verdadeiro conhecimento de si da vontade no todo através da representação do mundo como um todo. „Só quando ... um indivíduo que conhece se eleva a puro sujeito do conhecer e precisamente por aí o objeto considerado se eleva a Ideia é que aparece pura e inteiramente o mundo como representação; ocorre a objetivação perfeita da vontade..."16.

A partir dessa citação infere-se que o sujeito da contemplação estética é o

15 SCHOPENHAUER, A. WWV I, 210.

16 Idem, 211. 
sujeito transcendental, ao qual Schopenhauer retorna após ter percorrido as dificuldades advindas do vínculo entre o sujeito que conhece e o corpo. Também o artista não pode desfazer-se desse vínculo, embora ele o possa esquecer por alguns instantes. No entanto, o puro sujeito do conhecer diferencia-se em certa medida do sujeito transcendental, tal como este fora introduzido em sua vinculação com Kant. Enquanto o sujeito transcendental fora o correlato inapreensível das diversas classes de objeto do princípio de razão, o puro sujeito do conhecer, que em certo grau se conhece a si mesmo, é o correlato da Ideia. O sujeito transcendental, correspondendo às classes de objeto, fora nomeado entendimento, razão e sensibilidade, enquanto o puro sujeito do conhecimento, correlato da Ideia, é descrito apenas mediante um poder: a clarividência [Besonnenheit ${ }^{17}$. Originariamente um aspecto da razão comum, a clarividência ultrapassa o conhecimento a serviço da vontade, pois a clarividência [Besonnenheit] é a „força

17 Vertemos o termo Besonnenheit por "clarividência” devido à riqueza semântica que este termo de
origem francesa, clairvoyance, também possui em língua portuguesa. 0 dicionário Petit Robert atribui à palavra a seguinte acepção: "visão exata, clara e lúcida das coisas: acuidade, discernimento, fineza, 'flair', lucidez, perspicácia”. Trata-se de um termo que indica visão clara, daí poder-se perfeitamente dizer: “analisar a situação com clarividência”. Besonnenheit é por Schopenhauer empregado principalmente no domínio daquilo que compreende como intuição pura, gênio, mística. São momentos em que opera uma inflexão no termo, ou seja, retira-o do seu simples sentido de cautio, circumspection, Überlegung (ponderação) - sentidos que lhe são atribuídos pelo Deutsches Wörterbuch da língua alemã -, noutras palavras, retira-o do domínio semântico racional, da "consciência empírica", e o coloca na encruzilhada desta com a "consciência melhor". Nesse sentido, Besonnenheit remete, quando a faculdade de gênio é ativada, a uma visão intuitiva do todo da natureza, visão que é conservada em conceitos. É o que podemos observar na abertura do Tomo I de sua obra principal: "O mundo é minha representação: - esta é uma verdade que vale em relação a cada ser que vive e conhece, embora apenas o ser humano possa trazê-la à consciência refletida e abstrata: e se de fato o faz, então nele surge a clarividência filosófica." Aqui fica nítido que Besonnenheit não é o discernimento guiado pelo princípio de razão, mas designa o resultado, o surgimento de uma "consciência refletida e abstrata" porém depositária de algo não reflexivo, não racional, a intuição de natureza filosófica. Trata-se, conseguintemente, de uma espécie de terceiro estágio cognitivo, após a inocente intuição do entendimento, e a sopesada reflexão da razão. Terceiro estágio que conserva, entretanto, elementos dos dois anteriores. Por tudo isso, pela língua portuguesa nos brindar com esse galicismo, rico em sua ambiguidade, a minha opção por "clarividência" [Nota do tradutor]. 
do espírito"18 através da qual o conhecer liberta-se do serviço da vontade. Para sabermos mais sobre a „clarividência genial“ [geniale Besonnenheit], um olhar tem de ser lançado sobre o seu correlato, a Ideia.

O que Schopenhauer diz sobre a Ideia platônica, quando ele introduz o conceito no início do terceiro livro de sua obra principal, tanto em referência à coisa em si de Kant quanto a Platão, não parece ser claro nem particularmente elucidativo. A Ideia, como Schopenhauer escreve, é, como todo objeto, representação. "A Ideia apenas se despiu das formas subordinadas da aparência, as quais todas concebemos sob o princípio de razão; ou, para dizer de maneira mais correta, ainda não entrou em tais formas; porém, a forma primeira e mais universal ela conservou, a da representação em geral, a do ser-objeto para um sujeito." Se nos lembrarmos da forma universal do princípio de razão suficiente, que diz que nada pode se tornar objeto para nós que não possa ser relacionado a uma outra representação como seu fundamento, então essa definição de Ideia é impossível. Se a Ideia se despiu das formas „subordinadas“ da aparência, „cuja expressão geral é o princípio de razão"19, ela simplesmente cessa de ser objeto. Todavia, caso se leve em consideração a outra formulação, segundo a qual a Ideia „ainda não entrou [nas formas subordinadas da aparência]“, então isso nos remete de volta à circunstância de que o objeto da consciência de si na experiência decisiva do próprio corpo (o qual Schopenhauer primariamente descrevera como „objeto imediato“) não é o corpo espaço-temporal, mas antes o processo mesmo de objetivação. Visto que o conhecimento do próprio corpo como objetivação da vontade é a "chave para a essência de toda aparência na natureza"20, a intuição da Ideia, que desvela a essência, tem de ser compreendida como conhecimento do processo de objetivação.

Se se apreende desse modo o conceito de Ideia, cujas raízes descem lá atrás nas primeiras anotações de Schopenhauer presentes nos manuscritos póstumos, então muitas observações aparentemente contraditórias sobre a Ideia, que se espalham pela sua obra principal, são compreensíveis. Assim, Schopenhauer

\footnotetext{
${ }^{18}$ SCHOPENHAUER, WWV I, 210.

19 Ibidem.

20 SCHOPENHAUER, WWV I, 125.
} 
compara a Ideia, na medida em que ela se diferencia do conceito formado pela razão, a “...um organismo vivo desenvolvendo a si mesmo, dotado de força de reprodução, que produz o que nele não estava contido"21. A Ideia é, em certa medida, o meio caminho entre a completamente inintuível e inconcebível vontade como coisa em si e a sua aparência no espaço e no tempo. Ora, na medida em que, como vimos, o conhecimento sob o princípio de razão, conhecimento este limitado a meras relações, não está em condições de apreender de maneira alguma a essência das coisas, então a aparência comum é „apenas uma objetivação mediata da coisa em si (a vontade)" e, conseguintemente, objetivação inadequada, enquanto a Ideia expõe „a única imediata“ e por isso „mais adequada objetidade da

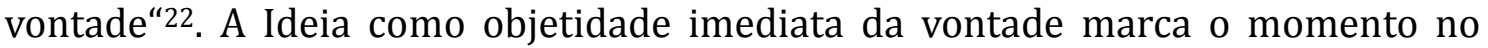
processo de objetivação da vontade no qual ele se torna acessível ao conhecimento, mas ainda não chegou ao estado no qual as ineludíveis condições subjetivas do conhecimento distorcem a apreensão das coisas.

A intuição do artista "é acompanhada de tal grau de clarividência [Besonnenheit] que ele reconhece nas coisas isoladas a Ideia, como que entende a natureza em suas meias palavras e, então, exprime puramente o que elas apenas balbuciam; ele imprime no mármore duro a beleza da forma em que a natureza fracassou em milhares de tentativas, coloca-a diante dela e lhe brada: "Eis o que querias dizer!"23.

Como a Ideia encontra-se entre a coisa em si e a aparência, então também o seu correlato, o puro sujeito do conhecer, nem deve ser identificado com o completamente incognoscível correlato do objeto, o „sujeito do conhecimento em sentido estrito", nem deve ele puro sujeito do conhecer ser visto como um sujeito de um „conhecimento imaculado" e completamente destacado da corporeidade. 0 puro sujeito do conhecer, assim, encontra-se entre os extremos da sua origem transcendental e do não alcançável ideal de um sujeito absoluto. A relação do assim definido puro sujeito do conhecer com o artista, que na citação de abertura aparece, sim, como identidade, devemos ainda considerar na conclusão.

\footnotetext{
${ }^{21}$ Idem, 277.

22 Idem, 206

23 Idem, 262.
} 


\section{d. 0 puro sujeito do conhecimento e a arte}

O puro sujeito do conhecer é qualificado através do livrar-se do serviço da vontade: o puro sujeito do conhecer, como diz Schopenhauer, é „livre de vontade“. Se nos lembrarmos que o sujeito que conhece, em Schopenhauer, está atado ao corpo, então é claro que não o sujeito enquanto tal e no todo pode ser livre de vontade, mas liberdade da vontade só pode descrever um estado do sujeito. Que durante o estado de puro conhecer o sujeito permanece fundamentalmente atado ao corpo, torna claro que esse estado só pode ser mantido por curto espaço tempo e com isso involuntariamente recai de novo no modo comum de conhecimento. Puro conhecer é como o voo de um peixe voador, que apenas por instantes pode permanecer no ar, para logo depois novamente retornar à água como o seu elemento natural.

Como já foi dito várias vezes, é a clarividência que capacita a alcançar o estado - no caso do gênio artístico - e nele tão duradouramente permanecer a ponto de a Ideia poder ser exposta em obra de arte. No entanto, a clarividência não é apenas a capacidade do gênio, mas também um poder de conhecimento que está sob o princípio de razão, a saber, a capacidade da razão de poder balancear entre si motivos como pensamentos independentes da sua real presença. Clarividência, portanto, é um poder que todo ser humano possui, já que o ser humano é definido, diferentemente dos animais, pela razão. Por conseguinte, a capacidade de tornar-se puro sujeito do conhecimento tem de "encontrar-se em todos os seres humanos, em menores e diversos graus, porque do contrário seriam tão incapazes de fruir as obras de arte como o seriam de produzi-las".

E, de fato, a maioria das pessoas estão em condições de fruir obras de arte e, com isso, por um lapso de tempo, tornarem-se puro sujeito do conhecer. Poderíamos, então, dizer que quase todas a pessoas possuem, em certo grau, gênio; mas esse não é o sentido em que Schopenhauer usa o conceito de gênio. Ao contrário, „a pessoa comum, esse produto de fábrica da natureza, que ela produz aos milhares todos os dias“, é por ele oposta ao gênio.] Pode apenas o „maior grau“ de clarividência que cabe ao gênio explicar essa oposição?

Schopenhauer define o gênio como „o grau mais elevado e a duração mais 
prolongada daquele modo de conhecimento, o que lhe permite conservar a clarividência necessária para repetir numa obra intencional o assim conhecido, repetição esta que é a obra de $\operatorname{arte}^{24}$. 0 artista também distingue-se pelo fato de poder manter a Ideia no espírito ali quando transita do puro conhecer para o conhecimento conforme o princípio de razão, em vista de instituir, de modo voluntário e intencional, a obra de arte. Em Parerga e paralipomena Schopenhauer escreve bem claramente, „[...] que o conhecimento artístico originário é um conhecimento completamente apartado, purificado, não volitivo, destituído de vontade... Ao contrário, na realização da obra, onde a comunicação e a exposição do assim conhecido é o fim, a vontade pode, sim, tem de ser novamente ativa, justamente porque um fim está aí presente: por conseguinte, predomina aqui também o princípio de razão..." Se o gênio é caracterizado pela capacidade de comunicação da Ideia, então o gênio é meio para um fim, e, de fato, Schopenhauer escreve que „a obra de arte é simplesmente um meio de facilitação“ do conhecimento que se origina da contemplação estética. É, no entanto, difícil de entender como uma única e mesma capacidade, a saber, a clarividência, que num elevado grau leva à libertação do conhecer em relação à vontade, deve num grau ainda mais elevado tornar-se um meio para uma atividade arbitrária.

Acrescida à clarividência é, por isso, ainda necessária uma outra capacidade em vista de esclarecer a produção artística, e, assim, também destacar o gênio artístico da fruição estética comum: a fantasia. 0 gênio precisa da fantasia „para ver nas coisas não o que a natureza efetivamente formou, mas o que se esforçava por formar, porém [...] não conseguiu levar a bom termo“25. Com essa definição da fantasia somos remetidos ao lado objetivo, a Ideia. Conforme a antes dada explicitação, a Ideia refere-se ao processo de objetivação da vontade. Se, com isso, a Ideia não pode ser objeto algum no sentido comum do termo, mas antes deve ser compreendida como o processo do vir-a-ser objeto, então a obra de arte não pode consistir numa imitação da Ideia; ou, dito de outro modo: o que o artista intencionalmente cria no tempo, no espaço e na matéria não pode ser uma imitação real da Ideia. Antes, obras de arte possibilitam que em nós emerja ou seja facilitada a consideração das Ideias. 0 artista „nos permite ver o mundo com seus

${ }^{24}$ Cf. Idem, 229.

25 Idem, 220. 
olhos“, de modo que podemos antecipar a beleza „antes da experiência“ (§ 45). A comunicação da Ideia pelo artista é alcançada através do „ideal“, que „é a Ideia, na medida em que esta, pelo menos em parte, é conhecida a priori e, enquanto tal, complementando o que é dado a posteriori pela natureza, torna-se prática para a arte." O poder que capacita o artista a mostrar a beleza, „como ele nunca a viu, e supera a natureza em sua exposição", é, como vimos, a fantasia. A fantasia, e não a clarividência, é, portanto, o elemento específico do artista. Evidentemente trata-se de um tipo especial de fantasia que, como "genial", deve ser diferenciada da imaginação comum que está a serviço da vontade. Mas seja como for, tem-se de constatar que a concepção schopenhaueriana do gênio artístico como puro sujeito do conhecer é estilhaçada [gesprengt] através do fato de que a característica específica do artista não é a capacidade para o puro conhecimento (pois tal capacidade ele a partilha com a pessoa comum, mesmo que a possua em grau mais elevado), mas a fantasia, que o coloca na situação de comunicar o puro conhecimento. 